\title{
SOCIEDADE EVANGÉLICA BENEFICENTE (SEB). MOVIMENTO DE COOPERAÇÃO ENTRE IGREJAS EVANGÉLICAS NO PARANÁ
}

\author{
Beneficent Evangelic Society: cooperation among \\ evangelic churches movement in Paraná
}

\author{
Agemir Carvalho Dias* \\ Valdinei A. Ferreira*
}

\begin{abstract}
RESUMO
O presente artigo tem por objetivo identificar as raízes da cooperação estabelecida entre as igrejas evangélicas de Curitiba. As raízes da cooperação evangélica remontam às missões norte-americanas e ao movimento unionista. A criação da Sociedade Evangélica Beneficente, em 1943, e a Campanha Pró-Hospital Evangélico serão o eixo principal da cooperação entre as igrejas evangélicas de Curitiba. As campanhas para a construção do Hospital Evangélico revelam uma complexa rede social. Para o êxito do empreendimento, foram mobilizados os recursos associativos e culturais da comunidade evangélica curitibana, bem como contatos junto ao poder público. Por fim, a edificação do hospital será parte da construção da própria identidade evangélica. A Sociedade Evangélica Beneficente será a face filantrópica e moderna dos evangélicos paranaenses.
\end{abstract}

Palavras-chave: evangélicos; saúde; cooperação.

\begin{abstract}
This paper aims at identifying the cooperation origins established among evangelic churches from Curitiba. The evangelic cooperation origins come from North American missions and from the unionist movement.

* Doutorando em História pela Universidade Federal do Paraná e professor da Faculdade Evangélica do Paraná. E-mail: agemir@terra.com.br

** Doutorando em Sociologia pela Universidade de São Paulo e professor da Faculdade Evangélica do Paraná. E-mail: valdinei@ usp.br
\end{abstract}


The Beneficent Evangelic Society creation, in 1943 and the Evangelic Pro-Hospital Campaign are the main support to the cooperation among evangelic churches of Curitiba. The campaigns to build the Evangelic Hospital show a complex social network. The evangelic community from Curitiba mobilized cultural and associative resources, as well as political contacts, to this project success. The Hospital building became part of the evangelic identity self-construction. The Beneficent Evangelic Society is the modern and the philanthropic evangelic face in Paraná.

Key-words: evangelic; health; cooperation.

\section{Introdução}

O Movimento Evangélico no Brasil ainda é um fenômeno pouco estudado, apesar do seu grande crescimento. Atualmente, vários estudos foram realizados a respeito de diversos aspectos do Protestantismo no Brasil. Há monografias sobre algumas igrejas e o seu relacionamento com a sociedade em geral. A obra educacional é lembrada por diversos autores. Há estudos sobre a participação política dos evangélicos, principalmente depois da Constituinte de 1988. Contudo, percebe-se um grande vácuo ainda nas pesquisas a respeito desse importante segmento religioso.

A história da participação dos evangélicos na área da saúde é um trabalho ainda por ser feito. Temos histórias de alguns hospitais evangélicos no Brasil contadas por pessoas que participaram da sua fundação ou do seu funcionamento, mas ainda não temos estudos acadêmicos a respeito.

Nossa investigação sobre a Sociedade Evangélica Beneficente procura justamente estabelecer os nexos entre evangélicos e saúde no contexto do Estado do Paraná e, em particular, a história do Hospital Universitário Evangélico de Curitiba, mantido por esta sociedade.

O Hospital Universitário Evangélico de Curitiba (HUEC) é um dos maiores hospitais do Paraná, que atende através do Sistema Único de Saúde (SUS) e que presta, desde 1959, quando foi inaugurado, relevantes serviços na área de saúde à sociedade paranaense.

O trabalho se propõe a mostrar o processo de inserção dos evangélicos no Paraná e, em especial, em Curitiba, como parte do movimento missionário moderno iniciado no final do século XVIII e começo do século 
XIX, com envio de missionários para a América Latina e Brasil. Procuramos demonstrar, também, que os missionários estabeleceram políticas de convivência e cooperação por meio da formação de instituições, buscando racionalizar os trabalhos, e que essa cooperação se mostrou eficaz na área da saúde.

A atuação na área da saúde fazia parte da estratégia missionária, mas também era a forma de se garantir um direito básico em uma área na qual o Estado ainda pouco atuava.

Limitaremos o estudo deste artigo ao período que vai da formação da SEB (1943) à inauguração do Hospital Evangélico de Curitiba (1959), demonstrando assim o esforço da comunidade evangélica de Curitiba no seu projeto humanitário de ação cristã.

\section{A inserção do protestantismo no Paraná}

Jean P. Bastian estabeleceu a tipologia abaixo da inserção do protestantismo $^{1}$ na América Latina. ${ }^{2}$

O protestantismo penetrou na América Latina no início do século XIX com o apoio discreto dos dirigentes liberais. Esses dirigentes permitiram a criação de escolas pelos protestantes e enviaram seus filhos para estudarem nelas. Os primeiros protestantes eram vendedores de Bíblias, pedagogos, comerciantes e homens de negócio. As primeiras igrejas protestantes eram destinadas primeiramente aos residentes estrangeiros.

No período seguinte, que se situa por volta da metade do século XIX, além das primeiras igrejas de estrangeiros, surgiram dois novos tipos de igrejas: (1) a imigração massiva de europeus de origem protestante, principalmente no Cone Sul, propiciou a formação das igrejas de imigrantes, geralmente de classe social muito modesta, que vieram tentar uma vida

1 Usamos as duas terminologias, evangélico e protestante, como sinônimos para efeito desse trabalho. A conceituação é complexa, pois algumas igrejas evangélicas não se consideram como um movimento vindo da Reforma Protestante e, da mesma forma, igrejas procedentes do movimento da Reforma Protestante não reconhecem algumas igrejas que se consideram evangélicas como sendo protestantes.

2 BASTIAN, Jean, P. Breve Historia del Protestantismo en America Latina. México: Casa Unida de Publicaciones, 1986. 
nova nos países em que se instalaram; (2) a missão das chamadas igrejas históricas (presbiterianas, batistas, metodistas, episcopais, luteranas), na sua maioria norte-americanas, que vieram motivadas pelo esforço conversionista de instalar suas igrejas em diversos países latino-americanos.

O terceiro período é o da decadência da influência européia e a consolidação da influência americana, já no início do século XX. Nesse período, surgiram diversas sociedades missionárias, chamadas de forma geral de “missões de fé”. Também continuou a onda migratória com a vinda de novas igrejas européias: Valdenses, Reformada Holandesa e Menonita.

Em meados do século XX, o movimento pentecostal começou a se tornar um verdadeiro fenômeno de massas em alguns países da América Latina, dentre os quais Brasil, México, Haiti, Chile e Guatemala.

No Brasil, o protestantismo na metade do séc. XIX era professado apenas por estrangeiros residentes. Nesse tempo, o movimento missionário moderno estava em franco desenvolvimento, com o envio de milhares de missionários para todas as partes do mundo.

Os primeiros missionários permanentes a aportarem no Brasil (1855) com o objetivo de estabelecer igrejas protestantes foram os congregacionais, com o missionário escocês Robert Reid Kalley ${ }^{3}$ e a sua esposa Sarah Kalley, que fundaram a Igreja Congregacional no Brasil (Igreja Evangélica Fluminense).

Depois vieram as missões presbiterianas com o missionário Ashbel Green Simonton, que chegou ao Brasil em 1859 e, em 1862, organizou a primeira Igreja Presbiteriana no Rio de Janeiro. Os metodistas estabeleceram-se definitivamente em 1886, com os missionários Junius E. Newman, John J. Ranson, J. W. Koger e James L. Kennedy. Os batistas iniciaram o seu trabalho missionário no Brasil em 1881, com Willian Bagby e Zacarias Taylor. Em 1889, chegaram os missionários episcopais Lucien L. Kinsolving e James W. Morris. Estes, depois de um acordo com os presbiterianos, estabeleceram-se no Rio Grande do Sul, de onde se expandiram.

As missões protestantes no Brasil foram frutos do movimento avivalista e, apesar do caráter denominacional, caracterizavam-se pela mesma ênfase teológica e metodológica dos avivalistas norte-americanos. Uma

3 Sobre o estabelecimento dos Congregacionais no Brasil por meio da atividade de R.R. Kalley indicamos o trabalho: CARDOSO, D. N. Robert Reid Kalley: médico, missionário e profeta. São Bernardo do Campo: Edição do Autor, 2001. 
ênfase na conversão individual, que não estava associada a um compromisso específico com uma igreja ou denominação.

No Paraná, Wilson Martins relata que a primeira presença do protestantismo como "religião organizada e proselitista" ocorreu por volta de 1845, com a passagem do missionário metodista Daniel P. Kidder, que teria evangelizado algumas pessoas que desembarcaram no porto de Paranaguá, quando da sua passagem pelo sul do Brasil. Em 1866, temos o relato da passagem de pregadores protestantes por Tibagi e Guarapuava, que provocaram a circular $n^{\circ} 59$, de 4 de março de 1886, expedida pelo vigário geral forense, o padre João Evangelista Braga, advertindo os católicos contra os pregadores protestantes. ${ }^{4}$ Júlio Andrade Ferreira informa que a primeira tentativa de levar o "Evangelho” ao Paraná pelos Presbiterianos foi feita pelo Rev. José Manoel da Conceição, um ex-padre e o primeiro pastor protestante brasileiro.

A primeira tentativa de levar o Evangelho ao Paraná foi feita pelo Rev. José Manoel da Conceição, que chegou até Castro, onde uma sua irmã era professora pública. Pouco se sabe do seu trabalho além do fato de ter pregado na cidade de Ponta Grossa. $^{5}$

Em 1885, a missão Presbiteriana contava com um missionário residente em Curitiba e com igrejas organizadas em Castro, Tibagi e Fundão. Os presbiterianos pregavam também em Campo Largo, Ponta Grossa e Guarapuava.

Ainda Martins relata que a presença protestante no Paraná se deu primeiramente através dos imigrantes alemães e ingleses, que nem sempre viam com bons olhos as ações dos missionários americanos. A primeira comunidade evangélica alemã no Paraná foi fundada em 1866, sendo J.F. Gaertner o seu primeiro pastor. ${ }^{6}$

Em 1943, quando da fundação da Sociedade Evangélica Beneficente (SEB), diversas igrejas evangélicas já se faziam representar em

4 MARTINS, Wilson. Um Brasil diferente. São Paulo: Anhembi, 1955. p. 401-402.

5 FERREIRA, Júlio Andrade. História da Igreja Presbiteriana no Brasil. São Paulo: Casa Editora Presbiteriana, 1959. p. 189.

6 MARTINS, Wilson, op. cit., p. 455. 
Curitiba: os Presbiterianos organizaram a sua igreja em 1888, a Igreja Presbiteriana Independente em 1904, os Batistas em 1914 e havia também missionários da Igreja Evangélica Congregacional e Igreja Metodista.

\section{A cooperação evangélica}

A primeira iniciativa de um projeto de cooperação entre os protestantes brasileiros foi a formação de um hospital evangélico em São Paulo. Em abril de 1890, reuniram-se alguns membros da $1^{\text {a }}$ Igreja Presbiteriana de São Paulo, em um salão da Escola Americana, com o plano de formar uma Sociedade Evangélica para a manutenção de um hospital. A comissão para angariar fundos ficou constituída pelo Dr. Horácio Lane, Rev. Eduardo Carlos Pereira, Manoel da Costa, Miss E. Kuhl e D. Maria Paes de Barros. O hospital projetado deveria ser interdenominacional, pois uma das razões alegadas para a construção do mesmo era o constrangimento pelos quais os evangélicos estavam sujeitos em outros hospitais de São Paulo. Assim, em 1894 é inaugurado o Hospital Samaritano de São Paulo, no bairro do Pacaembu. Outros hospitais evangélicos serão organizados no Brasil inteiro. O Hospital Evangélico do Rio de Janeiro foi inaugurado em 1912. ${ }^{7}$

Ainda em 1890, é formada a Liga Evangélica, que tinha como objetivo defender os direitos dos protestantes assegurados pelas instituições republicanas, pois eram constantemente ameaçados. Themudo Lessa relata casos de abusos como violação da liberdade de culto e o impedimento do sepultamento em cemitérios que haviam sido secularizados pela República como motivadores da formação da Liga. ${ }^{8}$

Em 1892, foi organizada a primeira Associação Cristã de Moços no Brasil (ACM). Myron A. Clark fundou no Rio a ACM, da qual foi presidente o estudante de medicina Nicolau Soares do Couto. Depois vieram as filiais de S. Paulo, Porto Alegre, Recife, Maranhão, Friburgo e Sorocaba.

Em 1902, foi formada a Aliança Evangélica de São Paulo, com o objetivo de desenvolver a propaganda por meio de folhetos, de artigos de

7 THEMUdo LESSA, V. Annaes da $1^{a}$ Egreja Presbyteriana de S. Paulo, p. 358.

8 Ibid., p. 359 
evangelização e de pregações ao ar livre. A Aliança Evangélica Brasileira foi constituída em 1903, sendo eleita a seguinte diretoria: o missionário metodista Hugh C. Tucker (presidente), o pastor batista F.P. Soren (secretário). Objetivava a Aliança Evangélica a promoção do testemunho cristão e a cooperação entre as igrejas evangélicas brasileiras. Themudo Lessa assim descreve a formação da Aliança Evangélica:

De 25 a 28 de julho reuniu-se em S. Paulo o Congresso Evangélico Brasileiro, convocado pela Alliança Evangélica de S. Paulo, por iniciativa do Rev. Dr. J. W. Tarboux. a sessão inaugural realizou-se na $1^{\text {a }}$ egreja com um auditorio calculado em 450 pessoas, pregando o Rev. Tarboux. Entre outros muitos ministros estiveram presentes às sessões o bispo Kinsolving, os Rev. Kyle e Gammon, F. F. Soren, W. E. Entzminger, Z. C. Taylor, Antonio Marques, J. L. Kennedy, H. C. Tucker e E. C. Pereira. ${ }^{9}$

Em 1916, foi realizado o Congresso do Panamá, que entregou ao comitê de cooperação, que tinha sido formado em Nova York, em 1913, pelas juntas missionárias, a tarefa de organizar os escritórios regionais, dentre os quais o do Brasil. Em 1916, logo após a Conferência do Panamá, ocorreu a Conferência Regional no Rio de Janeiro, na qual foram traçadas as linhas gerais para o protestantismo brasileiro: (1) organização de escolas pelas igrejas nacionais; (2) sustento próprio; (3) a formação de uma universidade para se alcançar as classes mais educadas; (4) a formação de um Seminário Unido.

O escritório regional do Brasil chamou-se "Comissão Brasileira de Cooperação” (CBC). Fundada em 1920, reuniu as Igrejas Congregacional, Presbiteriana do Brasil, Presbiteriana Independente, Metodista e Episcopal, tendo como Secretário Executivo o Rev. Erasmo Braga, que também era Secretário Executivo da Aliança Evangélica. Erasmo Braga dirigiu a CBC desde o início até sua morte, em 1932. Funcionava no mesmo prédio da União das Escolas Dominicais e da junta nacional das ACMs. A CBC chegou a reunir 19 entidades, entre igrejas, missões e organizações evangélicas cooperativas.

9 THEMUDO LESSA, V., op. cit., p. 654. 
A CBC realizou as seguintes atividades: elaboração de um cadastro atualizado dos pastores e igrejas em todo território nacional, estabelecimento de contatos internacionais, produção de literatura para Escola Dominical, desenvolvimento de projetos missionários para os indígenas, relacionamento com os movimentos sociais, criação do Seminário Unido e da Associação Umuarama em Campos do Jordão, publicação de livros. Além destas atividades, a CBC enviou Erasmo Braga como seu representante à Conferência Missionária em Jerusalém, promovida pelo Conselho Missionário Internacional. Erasmo Braga, sobre o êxito da iniciativa, fez o seguinte registro:

O público, fora das igrejas evangélicas, considera o nosso escritório como o centro do movimento evangélico do Brasil. O número de pessoas que ali buscam informações, pedem dados, buscam conselhos, já causa embaraços à regularidade dos nossos trabalhos. ${ }^{10}$

Em 1931, surgiu a Federação das Igrejas Evangélicas do Brasil, reunindo as igrejas que já faziam parte da CBC, com o objetivo de se articular frente às iniciativas da Igreja Católica em se tornar igreja oficial do Estado. Em 1925, a Igreja Católica tentou passar uma emenda constitucional com esse propósito. No Governo Getúlio Vargas, foi promulgado um decreto que permitiu o ensino religioso nas escolas públicas, bastando que vinte alunos requisitassem o mesmo. $\mathrm{O}$ decreto foi interpretado como sendo um primeiro passo para o fim do estado laico, defendido pelos protestantes no Brasil.

Depois da morte de Erasmo Braga, em 1934, as três principais organizações dos evangélicos no Brasil fundiram-se e formaram a Confederação Evangélica do Brasil (CEB). O seu primeiro secretário foi o Rev. Epaminondas Melo do Amaral, pastor da Igreja Presbiteriana Independente do Brasil, amigo e admirador de Erasmo Braga, que se tornou um dos principais nomes do movimento pela união das igrejas evangélicas no Brasil. O seu livro Magno Problema, de 1934, foi publicado pelo Centro Bra-

10 REILY, D. História documental do Protestantismo no Brasil, p. 257, trecho do relatório de Erasmo Braga, biênio 1927-28. 
sileiro de Publicidade. Nele, Amaral faz uma pungente defesa da união orgânica das Igrejas.

Em 1925, no Congresso de Ação Cristã na América do Sul, realizado em Montevidéu, que reuniu as diversas missões e igrejas protestantes que atuavam no continente, Robert Speer, então um dos mais importantes dirigentes do trabalho missionário nos Estados Unidos e um dos articuladores da cooperação missionária na América Latina, defendeu a importância do trabalho missionário médico como estratégia de evangelização na América Latina. A sua palestra no Congresso se intitulou: Medical missionary work in south América. Nela expôs a precariedade da saúde na América Latina e a atuação de missões cristãs com foco no atendimento da Saúde em diversos países da América do Sul. ${ }^{11}$

O Congresso de Montevidéu definiu o trabalho médico como uma das estratégias missionárias para a inserção do protestantismo na América Latina e despertou, em certa medida, uma ação social importante para o Protestantismo Brasileiro. Nos anos seguintes iniciou-se a abertura de diversos hospitais evangélicos no Brasil: Hospital Evangélico Goiano (1927); Hospital Evangélico de Pernambuco (1929); ${ }^{12}$ Hospital Evangélico de Rio Verde (1937); Hospital Evangélico de Sorocaba (1935); Hospital Evangélico de Curitiba (1943); Hospital Evangélico de Dourados (1946); Hospital Evangélico de Londrina (1948); Hospital Evangélico da Bahia (1961), entre outros.

Muitas dessas iniciativas tinham a característica da cooperação entre as diversas Igrejas Evangélicas (Pernambuco, Londrina, Curitiba). Outras eram desenvolvidas por missionários americanos, como o Hospital Evangélico de Rio Verde, que era uma base de trabalho da Igreja Presbiteriana dos Estados Unidos, dirigida pelo Dr. C. Gordon (1897-1998), e havia também hospitais iniciados por igrejas locais, como o Hospital Evangélico da Bahia, liderado pelos batistas.

Enquanto o trabalho educacional realizado pelos evangélicos permaneceu com características denominacionais, a obra hospitalar desenvol-

11 SPEER, Robert E. et al. Modern missions in Chile and Brazil. Philadelphia: The Westminster Press, 1926. p. 407- 419.

12 Os primeiros passos para a construção de um Hospital Evangélico em Pernambuco foram dados em 1901 e, em 1929, foi constituída a personalidade jurídica mantenedora do Hospital. Entretanto, somente em 1952 foram iniciadas as obras do Hospital e em 1954 a inauguração. As dificuldades enfrentadas em Pernambuco não eram exceções, mas a regra para as demais instituições evangélicas. 
veu-se com características de cooperação, reunindo primeiramente as igrejas envolvidas na Comissão Brasileira de Cooperação (CBC) e, posteriormente, na sua sucessora, a Confederação Evangélica do Brasil (CEB).

A organização da Sociedade Evangélica Beneficente (SEB) de Curitiba se deu no dia 25 de junho de 1943, na residência do Rev. Daniel Lander Betts. Estavam presentes João Emílio Henck, pastor da Igreja Batista, Alcides Nogueira, pastor da Igreja Presbiteriana, Jaime D. Cook, pastor da Igreja Congregacional, Dr. Parísio G. Cidade, pastor das igrejas presbiterianas em Joinville e São Francisco, A. Ben Oliver, missionário batista e Augusto Klopffleisch, presbítero da Igreja Presbiteriana de Curitiba. Nessa reunião, o Dr. Parísio Cidade propõe a criação de uma sociedade evangélica beneficente, com a finalidade da organização de um serviço médico hospitalar, com policlínica especializada, a fim de atender a comunidade evangélica e o povo em geral.

A primeira diretoria foi constituída pelos seguintes membros: Daniel L. Betts (presidente), Rev. Alcides Nogueira (secretário), João Emílio Henck (tesoureiro). Foram escolhidos como vogais A. Ben Oliver, Augusto Klopffleisch, Ireno Dionísio Reichelt, Dr. Parísio Cidade. Na ocasião registrou-se que não foi escolhido vice-presidente e que tal vaga seria reservada à Igreja Presbiteriana Independente, que não estava representada na reunião. ${ }^{13}$

A Cooperação se dava na perspectiva teológica da Confederação, mas a iniciativa era local, como nos relata o Rev. Parísio Cidade, médico e pastor presbiteriano, no seu relatório como presidente da sociedade, em 1947:

Prezados companheiros, o exercício de 1947 foi o das nossas realizações concretas, das vitórias maiores e das definições explêndidas, materializando-se o nosso ideal na concretização de coisas com que sonhávamos e por que vínhamos lutando idealmente. Como sabeis e devo confessar-vos, a idéia do Hospital Evangélico nesta cidade foi uma inspiração; e quero hoje dizer-vos francamente: “desejei o Hospital como um trabalho da Igreja Presbiteriana, a cujo ministério sirvo há mais de um decênio, num tributo de gratidão e apreço a

13 Histórico da SEB, f. 1. 
minha igreja". Achando porém que a obra do Bom Samaritano, grande inspiração do meu plano, não se prendia a um único grupo de fé, mas a um ideal de serviço sem cor partidária ou expressão denominacional, reuni os colegas, expus-lhes o meu plano e dessa mesa redonda surgiu, a serviço do próximo, no dia 25 de junho de 1943, a Sociedade Evangélica Beneficente - Pró Hospital Evangélico de Curitiba. [grifo dos autores] Éramos poucos a princípio: Daniel Lander Bettes, Ireno Dionísio Reichelt, Alcides Nogueira, João Emilio Henck, O. Ben Oliver, James Cook, Atílio Borio, Augusto Klopffleisch e 'eu'. ${ }^{14}$

Exemplifica ainda esta hipótese o fato da opção pela designação evangélico, que era a forma utilizada pela aliança evangélica para a identificação dos seus membros. ${ }^{15}$

A campanha da construção do Hospital Evangélico tornou-se um marco no trabalho de cooperação entre os evangélicos em Curitiba, foi abraçada com entusiasmo e exigiu os esforços das igrejas por cerca de duas décadas, em um trabalho inédito entre os evangélicos em Curitiba. O Relatório do Conselho da Igreja Presbiteriana de Curitiba para a Assembléia Ordinária anual da Igreja, ano de 1952, é um exemplo do espírito que envolvia as Igrejas Evangélicas de Curitiba:

MOVIMENTOS DE CONFRATERNIZAÇÃO
EVANGÉLICA. Quando as visitas do Rev. Miguel Rizzo Jr,
do Dr. Edwin Orr, do Rev. John Savage, ilustres visitantes que
realizaram trabalhos especiais entre os evangélicos de Curitiba,
bem como pela convenção das escolas Dominicais, Campanha
pró-hospital evangélico. Houve franca e perfeita
confraternização entre as diversas denominações de Curitiba.
Também por motivo das comemorações da semana da Bíblia,
houve intercâmbio espiritual com a Igreja Adventista da Capital.
Pregaram em nosso templo, na ausência do pastor, os Revs.
Wilbur Smith, Heinz Sobbol, Lauro de Queiroz e J. Timoteo da
Silva, respectivamente das igrejas Metodista, Luterana,

14 Evangélico informativo - 25/06/1993.

15 A Igreja Presbiteriana de Curitiba da Rua Comendador Araújo, no centro de Curitiba, cujo templo é do início do século vinte, mantém na sua fachada o dizer: Egreja Evangélica. 
Independente e Congregacional. O nosso pastor também pregou em todas estas igrejas e bem como, na Primeira Igreja Batista da Capital e colaborou com o Exército da Salvação em cultos ao ar livre. ${ }^{16}$

Em 1958, o Conselho da Igreja Presbiteriana de Curitiba continua manifestando a importância do Hospital Evangélico para a cooperação evangélica em Curitiba:

Continuamos a manter como que a liderança no movimento de confraternização evangélica, pois a nossa igreja, não só através do seu pastor, mas também de seus membros, mantém permanente contato e comunhão com as denominações irmãs. A obra do Hospital Evangélico é um campo muito propício para este encontro permanente com os outros irmãos. ${ }^{17}$

Esta obra comum exigiu um esforço muito grande durante vários anos, através de uma exaustiva campanha financeira que se prolongou até depois da inauguração do Hospital. Essa campanha aconteceu em diversas frentes. Contou com a mobilização de mulheres, através da formação da sociedade das Samaritanas, a mobilização de profissionais de saúde, liderados pelo ilustre médico Dr. Daniel Egg, pastores de diversas denominações, leigos das diversas igrejas e a participação do poder público.

\section{A campanha Pró-Hospital Evangélico}

Tendo examinado o movimento de cooperação entre as igrejas evangélicas brasileiras e os contornos que este movimento foi tomando, por

16 Arquivo da Igreja Presbiteriana de Curitiba, relatórios de 1950-59, pastorado do Rev. Osvaldo Soeiro Emrich, relatório do Conselho da Igreja de 1952.

17 Idem, relatório do Conselho da Igreja de 1958. 
meio da criação da Sociedade Evangélica Beneficente (SEB), na cidade de Curitiba, passamos agora à reconstituição historiográfica da Campanha PróHospital Evangélico. Trata-se de uma campanha que teve início em dezembro de 1943 e estendeu-se até os primeiros anos da década de sessenta. Embora tenhamos, grosso modo, cerca de duas décadas de mobilização em torno da construção do Hospital Evangélico, algumas etapas devem distinguidas. A primeira etapa tem início com a criação da própria SEB e estende-se até o lançamento da pedra fundamental do Hospital (1943-1947). É o período dos primeiros passos rumo ao ideal. Por outro lado, é também um período de afinação entre as lideranças evangélicas e ganho de knowhow na condução do movimento Pró-Hospital Evangélico. O segundo período estende-se de 1949 a 1959 e compreende a assinatura do contrato de Construção do Hospital Evangélico com a empresa "Construtura Técnica Industrial Ltda.” até a inauguração, em 1959.

\section{DA CRIAÇÃO DA SEB AO LANÇAMENTO DA PEDRA FUNDAMENTAL (1943-1947)}

Transcorridos exatos 25 dias após a criação da SEB, deu-se o primeiro esforço concreto para levantamento de recursos. Um grupo de senhoras, ${ }^{18}$ reunidas na casa da Sra. Clélia Calderari Boris, numa tarde de 15 de julho de 1943, criou o Departamento Feminino Pró-Hospital, denominado-o "Samaritanas”. A reunião resultou na constituição do primeiro grupo de trabalho feminino e na primeira oferta para a construção do Hospital, no valor de Cr\$22,00. O salário mínimo, ainda há pouco instituído no Brasil, fora fixado para o ano de 1943 em Cr\$ 300,00. Embora modesto, o primeiro esforço financeiro do departamento feminino era inspirador e apontava para o grau de mobilização da comunidade evangélica.

Alvo mais ambicioso seria estabelecido ainda naquele ano. Em 15 de dezembro de 1943, após a visita da Sra. Izabel Gomm, foi lançado o

18 As seguintes presenças, além da anfitriã, são mencionadas: Madalena Cercal, Carmem Wachelgue, Ceci Cidade, Emma Carvalho dos Santos, Francisca Betts, Angélica Baggio Santos, Lea Carvalho, Eugenia Cidade, Luci Nogueira e Sinhá de Almeida. (Histórico da SEB, f. 3) 
livro de ouro na residência do Sr. Blas Gomm e estabelecido o alvo de arrecadar Cr\$100.000,00. No relatório ${ }^{19}$ de 1948, menciona-se que a arrecadação obtida por meio do livro de ouro foi de Cr\$45.200,00.

Se nos anos de 1943 e 1944 conta-se tão-somente com ofertas, a partir de 1945 são iniciadas as contribuições sistemáticas dos sócios. A soma proveniente das mensalidades pagas pelos sócios é a seguinte: 1945 Cr\$ 13.288,00; 1946 - Cr\$ 15.374,00; 1947 - Cr\$ 15.259,00. A realização do levantamento de recursos por meio da contribuição voluntária dos sócios certamente foi facilitada pela cultura protestante do dízimo. Entretanto, a estrutura administrativa ainda incipiente e a oscilação no número de associados são percebidos como entraves para o aumento das contribuições.

Dentre os métodos para o levantamento de recursos destacamos também a realização da $1^{\mathrm{a}}$ Festa Beneficente promovida pelas Samaritanas. Todavia, no exame dos arquivos referentes à SEB, não encontramos a menção de outras festas beneficentes para o levantamento de recursos. Que esse mecanismo, tão largamente utilizado pelas obras de caridade católicas, não tenha sido privilegiado pelas igrejas integrantes da SEB, compreende-se à luz das peculiaridades da cultura protestante instalada no Brasil. ${ }^{20}$

No ano de 1945, serão dados os passos na direção da aquisição de um terreno para abrigar o futuro Hospital. Assim foi registrada a iniciativa da Diretoria da SEB:

Sabendo que na Interventoria do Estado estava um grande amigo nosso, o procuramos; primeiro, particularmente em sua residência, e depois, com uma Comissão em Palácio, para pedir ao Governo seu apoio a nossa obra. Não foi difícil a tarefa, pois o inolvidável Desembargador Clotário Portugal prontamente pôs à nossa disposição, pela Prefeitura de Curitiba, a cuja frente se encontrava o Dr. Algacyr Munhoz Maeder, uma excelente área de quase 4.000 metros quadrados, no aprazível bairro do Bigorrilho e bem próximo ao Hospital Militar de Curitiba. $^{21}$

19 Histórico da SEB, f. 5.

20 Para uma compreensão mais acurada da cultura protestante que se desenvolveu no Brasil ver MENDONÇA. A. G. O celeste porvir: a inserção do protestantismo no Brasil. São Paulo: Paulinas, 1984. MENDONÇA, A. G.; FILHO, P. Velazques. Introdução ao protestantismo no Brasil. São Paulo: Loyola, 1990.

21 Histórico da SEB, f. 3. 
A publicação do Decreto seria feita em 08/08/1947. A SEB apressou-se em adquirir também o terreno ao lado (lote 39-A). Desta forma, nos lotes 39-A e 39-B, situados à rua Augusto Stellfeld, os sonhos da comunidade evangélica curitibana começavam a ganhar forma.

O ponto alto da primeira fase viria a ser o lançamento da Pedra Fundamental. Às 15 horas do dia 07 de setembro de 1947 reuniram-se, no endereço acima citado, membros das igrejas evangélicas, pastores, autoridades políticas, militares e acadêmicas para o lançamento da Pedra Fundamental. As autoridades mencionadas são as seguintes: representante do Governador Moisés Lupion (nome não mencionado), Ângelo Lopes (prefeito de Curitiba), General Comandante do $5^{\mathrm{a}}$ Região Militar (nome não mencionado), José Pereira de Macedo (cientista) e deputados Julio da Rocha Xavier e Pinheiro Junior. ${ }^{22}$

A cerimônia foi conduzida pelo presidente da SEB - Rev. Parísio Cidade, pastor da Igreja Presbiteriana. Foi encarregado de proferir o discurso na ocasião o Prof. Dr. José Pereira de Macedo, apresentado como “um dos mais ilustres cientistas de nossa terra”. Na cerimônia reservou-se também espaço para o discurso a ser proferido pela oradora representante das Samaritanas. Julgamos significativa a palavra feminina na cerimônia de lançamento da Pedra Fundamental. Como vimos, as samaritanas realizaram o primeiro esforço de arrecadação.

Outra nota, referente à presença feminina, que deve ser destacada diz respeito à Sra. Izabel Gomm. Ela aparece nas atas da SEB como membro da Cruz Vermelha de São Paulo. A planta do Hospital, feita gratuitamente nos Estados Unidos, foi obtida por meio de sua intervenção. A aprovação da planta do Hospital pela prefeitura, em 1947, também contou com os préstimos da Sra. Izabel Gomm, bem como dos engenheiros Douglas Rhan (São Paulo) e Wenceslau Marinoski (Curitiba). A Sra Izabel Gomm foi a relatora da comissão de construção que, em 1949, selecionou a empresa vencedora da concorrência e aparecerá, a partir de 1948, como presidente de Honra da SEB.

O êxito da primeira etapa da jornada rumo à edificação do Hospital Evangélico transcende o âmbito municipal, tornando-se notícia em periódicos denominacionais de circulação nacional. É o caso da nota que extraí- 
mos do Jornal O Puritano, órgão de comunicação da Igreja Presbiteriana. A nota bem resume o espírito que predominava nas Igrejas Evangélicas de Curitiba por ocasião do lançamento da Pedra Fundamental:

Escreveu-nos a 7/09/47 o prezado irmão Dr. Atílio Bório informando-nos a cerimônia do lançamento da Pedra Fundamental do Hospital Evangélico de Curitiba em setembro do ano corrente.

Prezado Senhor Redator

Como vê vossa senhoria, diz o Dr. Bório, estamos em grande atividade visando cooperar na grande obra de assistência social. Todas as denominações evangélicas aqui estabelecidas se acham empenhadas nesse importante trabalho que se iniciou tão pequenino há cerca de 3 ou 4 anos e, hoje, já pode chamar a atenção da cidade para o lançamento da pedra fundamental de um edifício que, mercê de Deus, será um atestado eloqüente do idealismo, dos elevados sentimentos cristãos de nossa gente. Dia a dia aumentam as adesões. Nossa iniciativa despertou interesse de adeptos de todos os credos. Por essa forma esperamos aumentar o prestígio do protestantismo no Paraná. Já mandei dizer, repito agora, que temos um belo terreno e contamos com recursos para iniciar a grande obra, que, quando pronta, dotará Curitiba de um hospital moderno, com tudo quanto necessário seja para atender as necessidades de todos quantos o procurem.

Para cerimônia do lançamento da Pedra Fundamental foram convidadas todas as autoridades, o excelentíssimo senhor Moisés Lupion, governador do Estado, e irmão do nosso irmão João Lupion, Presbítero da Igreja de Itapetininga. ${ }^{23}$

O ano de 1948 foi de transição para a SEB. O Rev. Parísio Cidade, idealizador da SEB, apresentou no mês de agosto seu pedido de "renúncia em caráter irrevogável”, sendo acompanhado também pelo vice-presidente, Rev. João Emílio Henck. Assumia a presidência, interinamente, o Dr. Emanuel Coelho, que viria a ser eleito presidente na Assembléia Geral do dia 06/12/1948, realizada no templo da Primeira Igreja Batista. 


\section{DO LANÇAMENTO DA PEDRA FUNDAMENTAL À INAUGURAÇÃO (1949-1959)}

A SEB, ainda impulsionada pelos benefícios das primeiras conquistas, materializadas no lançamento da Pedra Fundamental, lançou-se à segunda etapa da Campanha Pró-Hospital. A questão crucial que se coloca nessa fase - de onde virá o dinheiro?

Antes de entrarmos na análise dos caminhos percorridos para o levantamento de recursos, convém recordar a natureza associativa das igrejas protestantes. Na cultura protestante, a igreja é uma associação voluntária. Os fiéis aderem à igreja, o que implica em compromisso na manutenção da estrutura e funcionamento dos serviços religiosos. Deste modo, constituem-se rotinas desse universo religioso a formação de juntas e/ou comissões de construção e a realização de assembléias para deliberação sobre assuntos administrativos e religiosos da comunidade. O registro das observações acima tem por finalidade lembrar-nos que a mobilização feita em prol da construção do Hospital colocou em ação um conjunto de mecanismos e técnicas de associação que já estavam presentes na rotina das igrejas integrantes da SEB.

\section{A fase doméstica: os sócios e as campanhas}

A contribuição mensal de associados é um dos primeiros mecanismos para o levantamento de fundos. Os valores das contribuições partiam de Cr\$ 5,00 e alcançavam Cr\$ 50,00. A ampla faixa das contribuições, de pouco mais de $1 \%$ até $16 \%$ do salário mínimo da época, possibilitava a participação de pessoas de todas as classes. À medida que a construção do Hospital se inicia, o número de contribuintes associados também aumenta, como se vê na tabela a seguir:

\begin{tabular}{|l|l|}
\hline ANO & N $^{\circ}$ DE SÓCIOS \\
\hline 1949 & 432 contribuintes \\
\hline 1949 & 806 contribuintes (fim do ano) \\
\hline 1950 & 962 contribuintes \\
\hline
\end{tabular}




\begin{tabular}{|l|l|}
\hline 1951 & 1.063 contribuintes \\
\hline 1952 & 1.125 contribuintes \\
\hline 1953 & 1.208 contribuintes \\
\hline 1958 & 2.849 contribuintes \\
\hline
\end{tabular}

Em 1958, registra-se ${ }^{24}$ que $67 \%$ dos contribuintes associados são membros das igrejas evangélicas. Embora significativamente concentrada nos evangélicos, já se percebe que a Campanha Pró-Hospital possui simpatizantes e contribuintes fora dos limites confessionais. Aliás, com freqüência as atas registram que a Campanha contava com a simpatia da população.

Além de transbordar as fronteiras confessionais, a causa Pró-Hospital ganha contribuintes fora do Município de Curitiba. São mencionadas contribuições mensais vindas das seguintes cidades paranaenses: Ponta Grossa, Antonina, Paranaguá, Morretes, Castro, Piraí do Sul, Carambeí, Prudentópolis, Sengés e Irati. As igrejas evangélicas implantadas nestas cidades, ao lado dos laços familiares, funcionavam como pontos de contato.

Um ponto importante a ser lembrado na dinâmica de cooperação entre os evangélicos é o aspecto da mútua cooperação. O Hospital que se erguia em Curitiba pela SEB viria preencher lacunas do precário sistema de saúde brasileiro de meados do século XX. Desde sua idealização, faz-se recordar que atenderá os evangélicos, mas estará sempre de "portas abertas aos que sofrem e necessitam de um lenitivo para suas vidas”. ${ }^{25}$ Pois bem, aqueles que constroem o Hospital também carecem de atendimento médico de qualidade. Então, assim como os laços de fraternidade evangélica irmanam os envolvidos no processo de mobilização, também vão sendo construídas outras fontes de solidariedade. Exemplo disso é o trecho que se segue:

ASSISTÊNCIA SOCIAL - Enquanto não tivermos o nosso Hospital, é justo que os nossos associados tenham alguma vantagem no que diz respeito ao serviço de assistência social. Tendo em vista o grande número de sócios, o Conselho resolveu encarregar o Dr. Daniel Egg para conseguir um abatimento, 
dos médicos, dentistas, laboratórios, hospitais e casas de saúde, para todos os associados. A missão do Dr. Daniel foi coroada de pleno êxito, pois conseguiu o seu objetivo com os melhores médicos de Curitiba. Além disso, o ambulatório da Igreja Presbiteriana e Batista, sob a direção do Dr. Daniel Egg, auxiliado pelos acadêmicos Evangélicos, tem atendido centenas de necessitados de nossas igrejas, fornecendo remédios gratuitos, bem como às pessoas não evangélicas de parcos recursos. ${ }^{26}$

Os valores arrecadados por meio das mensalidades (para ilustrar, ano de 1950 - Cr\$ 66.551,00; 1951 - Cr\$ 72.101,00; 1952 - Cr\$ 93.156,50) são importantes para a manutenção das atividades da SEB. Para fazer frentes a despesas mais vultosas, serão colocadas em ação as campanhas. O orçamento apresentado pela Construtura Técnica Industrial Ltda., em 1949, era de Cr\$ 3.500.000,00. Evidentemente não seria possível executá-lo apenas com as mensalidades dos contribuintes. Embora as mensalidades não pudessem dar conta do montante de uma construção desse porte, julgamos que a constituição de um grupo de associados foi fundamental para fornecer uma base de mobilização social para as campanhas. Estas sim, haveriam de alavancar o projeto de construção. Até a inauguração do Hospital foram realizadas 8 campanhas, com os seguintes resultados:

\begin{tabular}{|c|c|}
\hline $1^{\text {a }}$ Campanha - 1952 & Cr\$ 362.173,50 \\
\hline 2a Campanha - 1953 & Cr\$ 699.840,00 \\
\hline $3^{\text {a }}$ Campanha - 1954 & Cr\$ 719.712,50 \\
\hline $4^{\text {a }}$ Campanha - 1955 & Cr\$ 792.055,00 \\
\hline $5^{\text {a }}$ Campanha - 1956 & Cr\$ 748.247,00 \\
\hline 6 Campanha - 1957 & $\mathrm{Cr} \${ }^{27}$ \\
\hline $7^{\mathrm{a}}$ Campanha - 1958 & Cr\$ 1.124.494,00 \\
\hline $8^{\text {a }}$ Campanha - 1959 & Cr\$ $1.000 .000,00^{28}$ \\
\hline
\end{tabular}

26 Livro de Atas da Assembléia Geral da SEB, n. 2, f.4.

27 Não foi possível localizar nas atas o valor obtido na $6^{a}$ campanha. Entretanto, temos razões para crer que tenha ficado na média das demais campanhas.

28 Quanto à 8 a Campanha, realizada no ano da inauguração do Hospital, foi feito o seguinte registro: "No início de 1959, realizamos a Campanha de Empréstimos Internos - movimento entre o meio evangélico no sentido de conseguir empréstimos a fim de fazer face às dificuldades que vínhamos encontrando para conseguir meios de urgente necessidade para que o Hospital pudesse entrar parcialmente em 
Apenas os números citados acima não traduzem o cotidiano das Campanhas na comunidade evangélica. Em geral, o pastor e/ou diretoria da igreja designavam pessoas da comunidade que se encarregavam de liderar a campanha financeira Pró-Hospital. Alguns pequenos trechos, extraídos do cotidiano de uma das igrejas participantes, ajudam a aclarar o significado, o grau de envolvimento e, por que não, a finalidade pedagógica das campanhas:

\section{"CAMPANHA PRÓ-HOSPITAL”}

A nossa Igreja participou com destaque dessa campanha com uma equipe de consagrados líderes e cooperados, basta dizer que, dos Cr\$ 600.000,00 levantados pela campanha, metade foi angariada pelas equipes de nossa igreja, lideradas respectivamente pelo Dr. Emanuel Coelho, Augusto Klopffleisch e Da. Olinta Palmquist. ${ }^{29}$

\section{“COFRES"}

Por iniciativa de Dna. Olinta Palmquist, foram distribuídos os cofres para o Hospital Evangélico e para o Natal dos pobres, rendendo, respectivamente, Cr\$1.946,90 e 3.310,60. Este trabalho, realizado principalmente pelas crianças, tem a finalidade de educá-las para trabalhar por estas nobres causas. ${ }^{30}$

\section{“CAMPANHA DO HOSPITAL EVANGÉLICO”}

Prossegue animada e vitoriosa, mas dependendo da sua colaboração.

- Você ainda não é contribuinte:

- Não diga!!!

- Deixe-me apresentá-lo à Dona Olinta Palmquist... ${ }^{31}$

funcionamento. É verdade que o alvo proposto não foi atingido, porém o resultado desta Campanha foi satisfatório e veio proporcionar a possibilidade de intensificar as obras do Hospital, atingindo a Campanha um total de mais de um milhão de empréstimos”. (Histórico da SEB, f. 12)

29 Arquivo da Igreja Presbiteriana de Curitiba, relatórios de 1950-59, pastorado do Rev. Osvaldo Soeiro Emrich, relatório do Conselho da Igreja de 1952.

ras.

30 Arquivo da Igreja Presbiteriana de Curitiba - 1950-59. Relatório da Sociedade de Senho-

31 Boletim Dominical da Igreja Presbiteriana de Curitiba, 13/09/1959. 
Outros espaços, além daqueles estritamente religiosos, são ocupados e outros recursos culturais das igrejas são postos a serviço das campanhas. É o caso de concertos musicais, recitais de piano e apresentações de canto coral. O Boletim da Igreja Presbiteriana Central assim anunciava um desses eventos: "O CORAL EVANGÉLICO dará dois concertos no Teatro Guaira, nas noites de 25 e 26, com orquestra e novos cânticos sagrados, em benefício do Hospital Evangélico. Todos são convidados."32

As diferentes modalidades de contribuição com a causa Pró-Hospital (mensalidades, campanhas, cofres para crianças, concertos) mostram a amplitude do engajamento das igrejas integrantes da SEB.

\title{
Batendo à porta do Palácio: os primórdios da cidadania
}

Concomitantemente às campanhas financeiras, vai se constituindo a consciência de que os poderes municipal, estadual e federal também podem colaborar com a causa nobre da edificação do Hospital Evangélico. O seguinte registro foi feito:

\begin{abstract}
A Sociedade Evangélica Beneficente tem recebido subvenções dos poderes públicos, a exemplo dos anos anteriores. Ano de 1958, a Sociedade recebeu do Governo Federal a importância de $\mathrm{Cr} \$ 50.000,00$ e da prefeitura Cr\$25.000,00. Pelo exposto, notamos que também os poderes públicos não se esquecem da importância da obra do Hospital Evangélico, e assim ela poderá chegar a bom termo, no que concerne ao término da construção. ${ }^{33}$
\end{abstract}

As contribuições feitas pelos poderes públicos estão longe de serem somas vultosas. Apenas para recordar - somente em 1958 a campanha feita pelas igrejas angariou mais de um milhão de cruzeiros. Entretanto, a SEB vai se fazendo aos poucos conhecida no âmbito do poder público. 
Para isso contribuíram lideranças evangélicas, tais como o Rev. Zaqueu de Melo (deputado estadual) e o Dr. Lauro Monteiro da Cruz (deputado federal e presbítero da $1^{\mathrm{a}}$ Igreja Presbiteriana Independente de São Paulo).

Na Assembléia Geral Ordinária de 05/03/1958, a SEB decide dedicar maior atenção às relações públicas com as autoridades administrativas. De tal iniciativa nasceram os convites e as visitas às obras do Hospital do Ministro da Saúde, do Governador, do Prefeito Municipal e do Secretário de Saúde Municipal. Registrou-se ainda que, como efeito de tais contatos, as subvenções para o ano de 1960 foram aumentadas significativamente. ${ }^{34}$

\section{Peregrinando no estrangeiro}

Os laços transnacionais das igrejas evangélicas foram também mobilizados com êxito em prol da construção do Hospital Evangélico. Colaboraram com as primeiras iniciativas o Rev. Oswaldo Soeiro Emmerich e o Dr. Daniel Egg. O Rev. Oswaldo esteve nos EUA em 1957 para cursar pós-graduação em Teologia. Na ocasião, conseguiu junto ao Rev. Cecil Thomson, do Seminário de Columbia, Geórgia, a doação de uma ambulância, um aparelho de Raio X e um eletrocardiógrafo. ${ }^{35}$ Depois de muita dificuldade com a burocracia brasileira, conseguiu-se trazer a ambulância. Posteriomente, a ambulância foi vendida e adquirido um veículo nacional para ambulância e a sobra de recursos, aplicada na construção. Do Dr. Daniel Egg também ficou registrado que conseguiu donativos para o Hospital.

A colaboração de entidades evangélicas estrangeiras foi ampliada depois de 1960. Não é nosso intento examiná-las aqui, uma vez que nos propomos à análise de 1943 a 1949. Entretanto, deve-se mencionar a viagem do Sr. Willy Haeusur, então administrador do Hospital, aos EUA e Canadá, em 1962. Pouco depois serão estabelecidos contatos com a Central Evangélica Alemã.

34 Histórico da SEB, f. 14.

35 Id. 


\section{Conclusão: imagens do hospital que animaram os primeiros anos de construção}

Nas memórias da fundação da SEB, quanto ao ideal da construção do Hospital Evangélico, encontramos a seguinte reflexão: “... Fazíamos, habitualmente, reuniões mensais de oração, reunindo o povo de Deus e os amigos, cada vez numa igreja, para orar pela obra do Hospital. Tudo ainda era visão e nada se via claramente... uma esperança porém todos alimentávamos. "36 À medida que os passos na direção da concretização da visão foram sendo dados, as imagens do Hospital foram aparecendo. Referimonos não apenas à imagem real da edificação, mas às imagens que as igrejas foram construindo do Hospital para alimentar os doze anos de campanha.

Fala-se do Hospital que se ia construindo como um "majestoso templo de renovação física, moral e espiritual", como a "estrela da caridade" $^{\text {"37 }}$ que começa a resplandecer na cidade de Curitiba. Esta última era uma alusão ao formato de estrela da planta do Hospital. Deixando o campo das representações religiosas, a opinião dos técnicos é citada para testemunhar que o “Hospital 'Samaritano' de Curitiba será um 'Hospital' padrão para o Brasil, pois a sua planta foi trazida dos Estados Unidos pela Da Izabel Gomm, da Cruz Vermelha de S. Paulo". ${ }^{38} \mathrm{O}$ Hospital também é retratado como moderno e como expressão de uma época, feita com auxílio divino e para a geração futura. ${ }^{39}$

Essas são representações que a comunidade foi construindo para si. Falam da obra, mas falam também dos autores da obra. Ao edificar o Hospital a comunidade edifica a si mesma. Constrói-se como comunidade de fé que oferece assistência social, mas o faz de forma inovadora e moderna. 
Ilustração 1 - Membros da SEB em 1944

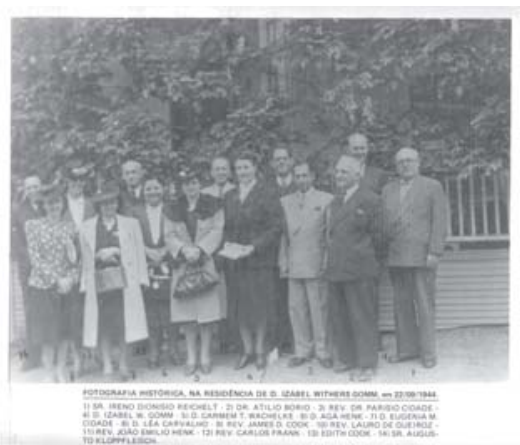

Ilustração 2 - Estágio da construção em 1955

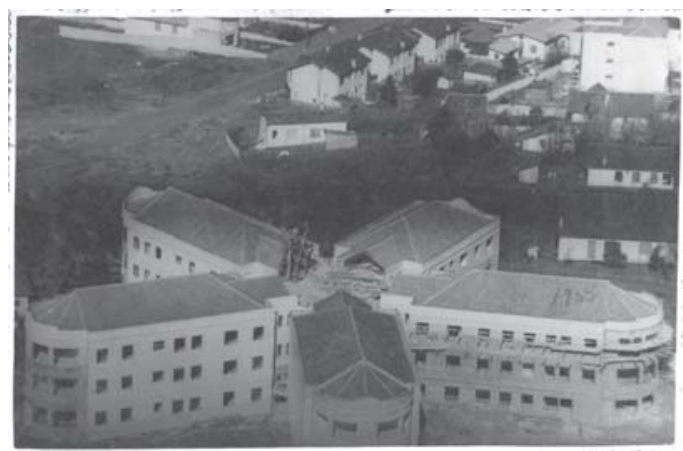

Ilustração 3 - Primeira ambulância do Hospital Evangélico

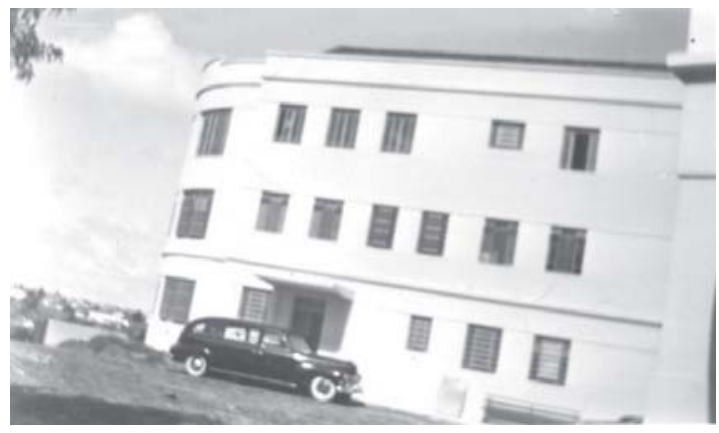

